\title{
Differences in hip morphology between the sexes in patients undergoing hip resurfacing
}

Henry D Atkinson ${ }^{1,2^{*}}$, Karanjeev S Johal ${ }^{1}$, Charles Willis-Owen², Steven Zadow ${ }^{2,3}$, Roger D Oakeshott ${ }^{2}$

\begin{abstract}
There is limited morphological data on the sex differences between the commonly used pelvic parameters. This study analysed the CT scans of 100 consecutive Caucasian patients, 61 males and 39 females, undergoing hip resurfacing arthroplasty surgery for hip osteoarthritis in one institution.

There were no sex differences in femoral torsion/anteversion, femoral neck angle and acetabular inclination. Males had a mean femoral torsion/anteversion of 8 degrees (range -5 to 26 degrees), a mean femoral neck angle of 129 degrees (range 119 to 138 degrees) and a mean acetabular inclination of 55 degrees (range 40 to 86 degrees). Females had a mean femoral torsion/anteversion of 9 degrees (range -2 to 31 degrees), a mean femoral neck angle of 128 degrees (range 121 to 138) and a mean acetabular inclination of 57 degrees (range 44 to 80 degrees). Females had a significantly greater acetabular version of 23 degrees (range 10 to 53) compared with 18 degrees in males (range 7 to 46 degrees $(p=0.02$ ) and males had a significantly greater femoral offset of $55 \mathrm{~mm}$ (range 42 to $68 \mathrm{~mm}$ ) compared with $48 \mathrm{~mm}$ (range 37 to $57 \mathrm{~mm}$ ) in females $(p=0.00)$. There were no significant differences between measurements taken from each patient's right and left hips.

These findings may be useful for the future design and the implantation of hip arthroplasty components.
\end{abstract}

\section{Introduction}

Metal on metal hip resurfacing is a modality of treatment that been shown to be an effective medium term solution for young adults with hip osteoarthritis[1]. Its principle is to preserve femoral bone stock and thus make any future revision surgery more amenable [2].

Accurate placement of the hip resurfacing components has an impact on the clinical outcomes. In particular, varus angulation of the femoral component and femoral neck notching have been shown to be risk factors for neck of femur fracture [3], and inadequate cup anteversion has a significant impact on hip flexion and edge loading [4].

Pre-operative calculations of femoral torsion, version and offset as well as acetabular version and inclination have been previously undertaken using plain radiographs $[5,6]$, and subsequently more accurately using CT scanning [7]. The use of CT guidance in the placement of prostheses has been shown to significantly improve the

\footnotetext{
* Correspondence: dusch1@gmail.com

'Department of Trauma and Orthopaedics and North London Sports Orthopaedics, North Middlesex University Hospital, Sterling Way, London N18 1QX, UK

Full list of author information is available at the end of the article
}

post-operative component positions compared with freehand techniques [8]. CT scanning may also identify other anatomical anomalies and the presence of femoral head/neck cysts that may not be apparent on plain radiography [9].

Differences between male and female pelvic morphology may also be an important factor. Studies in childhood have demonstrated no difference in femoral anteversion between the sexes [10], however there may be differences in adults [11-17]. There continues to be very limited data on the sex differences between the commonly used pelvic parameters.

This study prospectively collected data from the CT scans of 100 consecutive Caucasian patients undergoing hip resurfacing for early osteoarthritis, analysing each of the patient's two hips for femoral neck angle, torsion and offset, and acetabular inclination and anteversion, and comparing the sexes. This, to our knowledge, is the first study of its kind.

\section{Patients and Methods}

100 consecutive Caucasian patients, 61 males and 39 females (mean age 52 and 54 respectively), underwent pelvic CT scanning as part of their routine work-up for 
hip resurfacing arthroplasty surgery for hip osteoarthritis, between March 2007 and October 2008 in one institution.

The radiographic measurements were performed by two independent investigators. Repeated measurements were also taken in a random order to check for intraobserver error. The radiographic parameters measured included the femoral neck angle, femoral torsion, femoral offset, acetabular version and acetabular inclination.

The acetabular inclination was calculated by plotting a trans-ischial line on the pilot image, and a second line drawn across the superior and inferior rims, across the face of the bony acetabulum [18]. The inclination angle was formed by the intersection of these lines (Figure 1).

The acetabular version was calculated by plotting a trans-ischial line across the ischial tuberosities on the axial CT image. The trans-ischial line was then transposed to an axial image of the acetabulum, and a second line was drawn across the anterior and posterior margins of the bony acetabulum. The anteversion angle was formed by the intersection of these two lines (Figure 2).

The femoral torsion was determined by plotting a reference line through the transcondylar plane of the distal femur, and plotting a second line through the axis of the neck of the femur. Superimposition of these lines gave the femoral torsion angle (Figure 3).

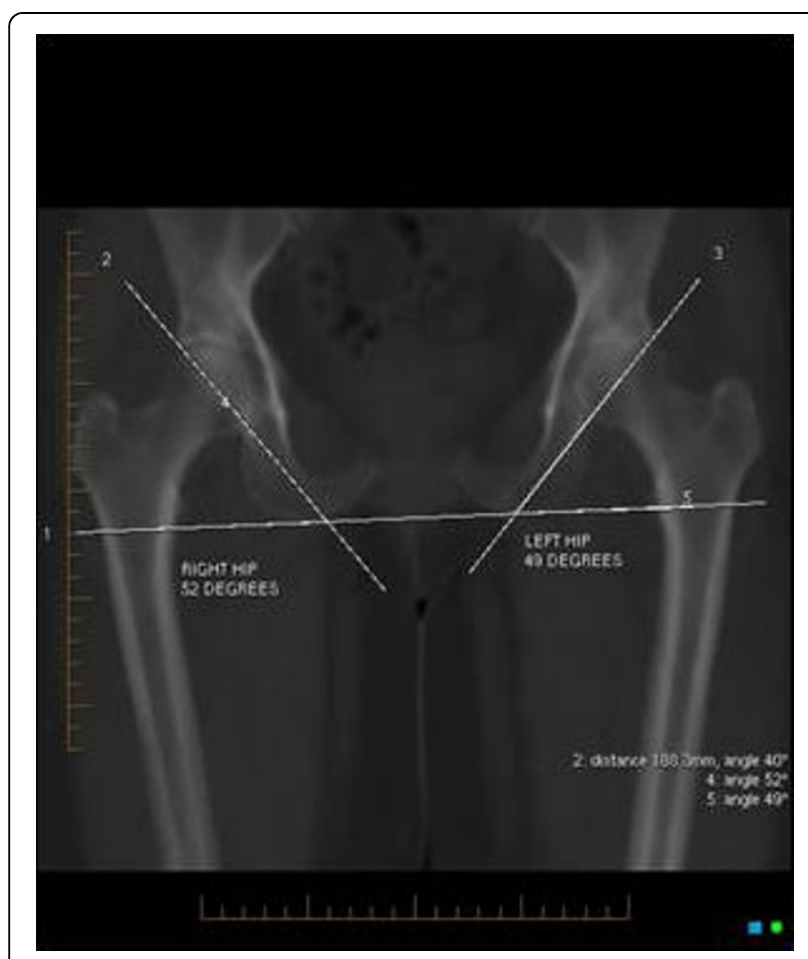

Figure 1 The acetabular inclination calculated by plotting a trans-ischial line, and intersecting this with a second line drawn across the superior and inferior acetabular rims.

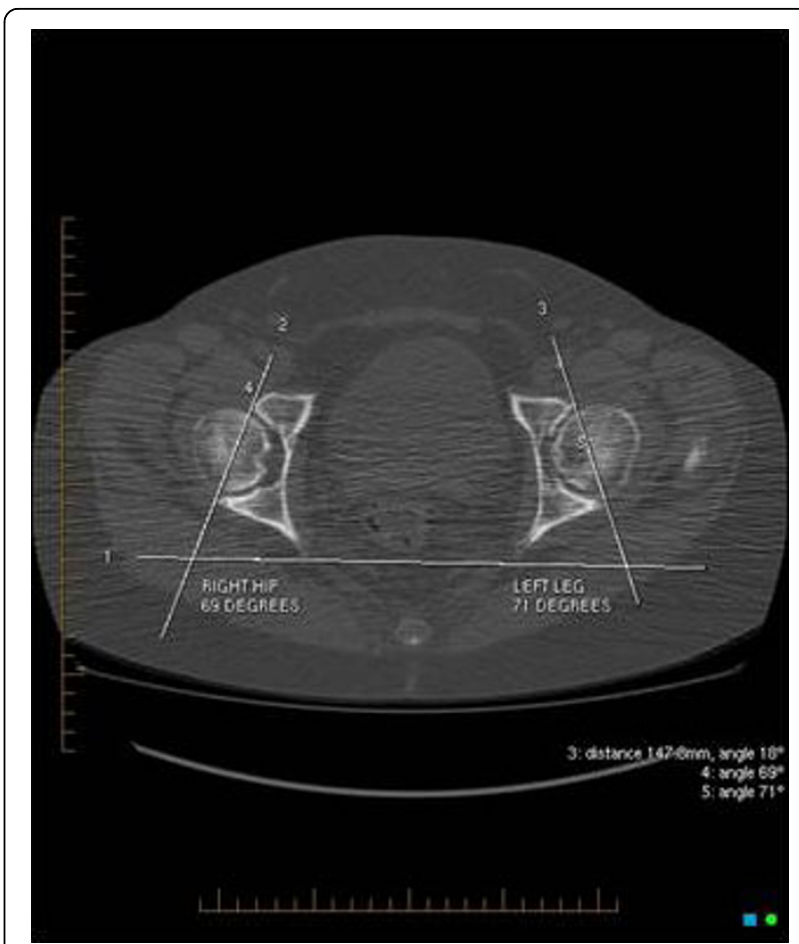

Figure 2 The acetabular version calculated by plotting a transischial line across the ischial tuberosities on axial CT image. A second line is drawn across the anterior and posterior margins of the bony acetabulum. The anteversion angle is formed by the intersection of these two lines.

The femoral neck angle was determined by plotting a line along the axis of the femoral neck and a second line along the long axis of the femur. The transection of these lines gave the femoral neck angle (Figure 4).

The femoral offset was determined as the distance from the centre of rotation of the femoral head to the line bisecting the long femoral axis (Figure 5) [19].

Data were statistically analyzed using the Friedman non-parametric test allowing for two-way analysis of variance, after Kolmogorov-Smirov analysis. Data were also analyzed using the Wilcoxon Signed Ranks Test. A 2-tailed comparison was made of patients' left and right hip data using Spearman's correlation tests.

\section{Results}

The analyzed results demonstrated no sex differences in femoral torsion/anteversion, femoral neck angle and acetabular inclination (Table 1 ). Males had a mean femoral torsion/anteversion of 8 degrees (range -5 to 26 degrees), a mean femoral neck angle of 129 degrees (range 119 to 138 degrees) and a mean acetabular inclination of 55 degrees (range 40 to 86 degrees). Females had a mean femoral torsion/anteversion of 9 degrees (range -2 to 31 degrees), a mean femoral neck angle of 128 degrees (range 121 to 138) and a mean 


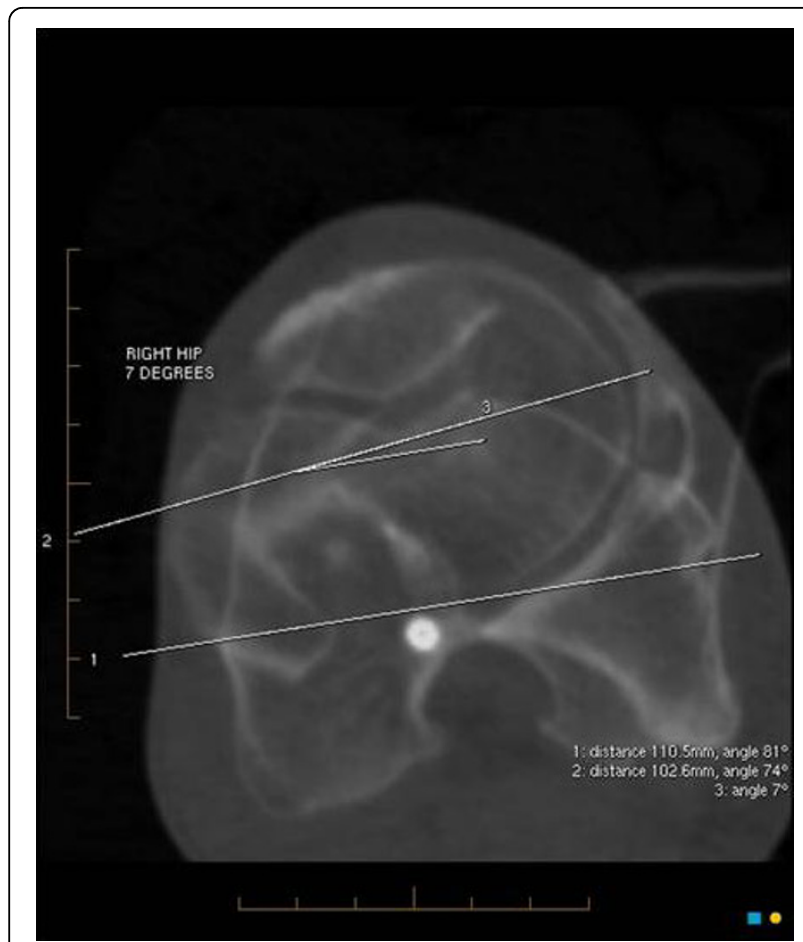

Figure 3 The femoral torsion is determined by plotting a reference line through the transcondylar plane of the distal femur, and superimposing a second line through the axis of the neck of the femur.

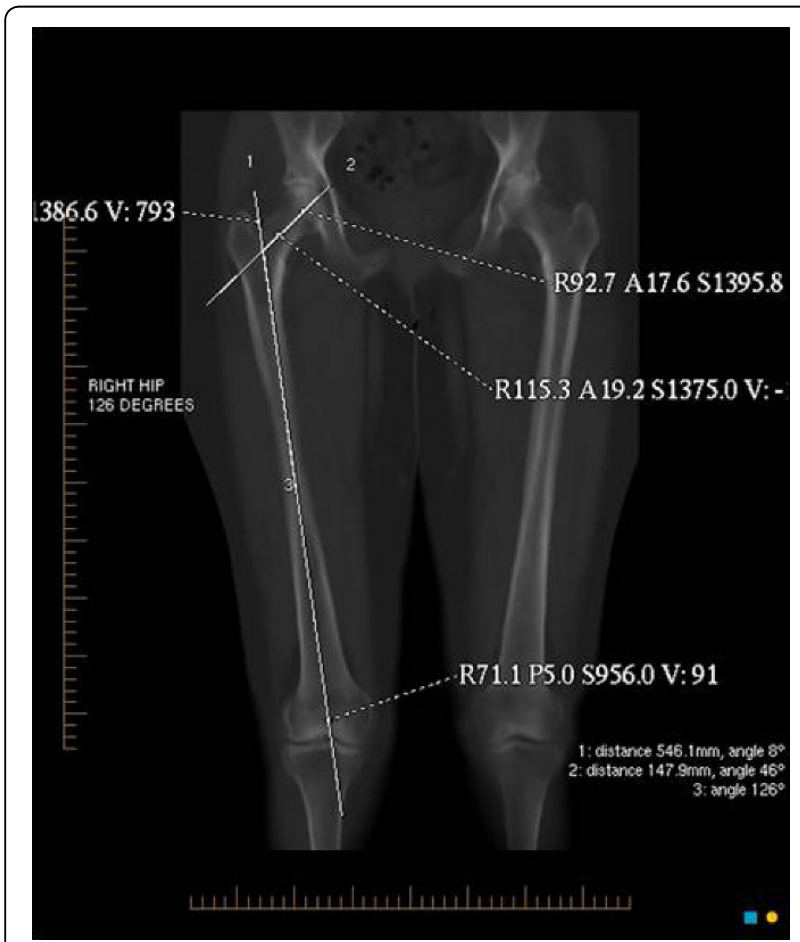

Figure 4 The femoral neck angle determined by plotting a line along the axis of the femoral neck and a second line along the long axis of the femur.

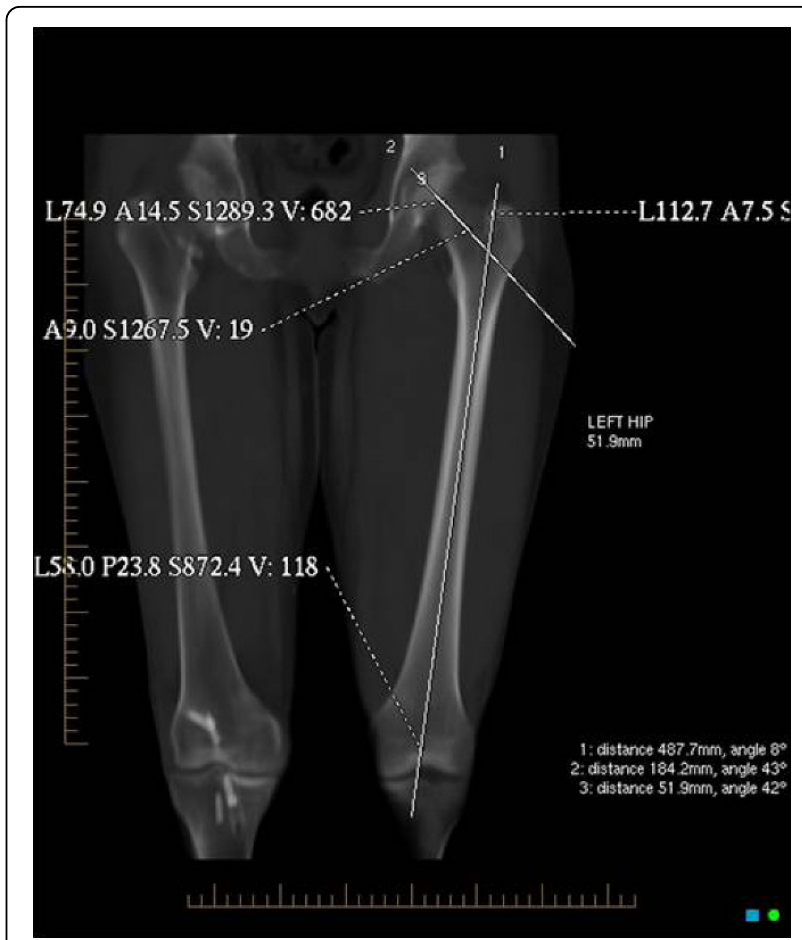

Figure 5 The femoral offset determined as the distance from the centre of rotation of the femoral head to a line bisecting the long femoral axis

acetabular inclination of 57 degrees (range 44 to 80 degrees).

Females had a significantly greater acetabular version of 23 degrees (range 10 to 53) compared with 18 degrees in males (range 7 to 46 degrees $(\mathrm{p}=0.02)$ and males had a significantly greater femoral offset of 55 $\mathrm{mm}$ (range 42 to $68 \mathrm{~mm}$ ) compared with $48 \mathrm{~mm}$ (range 37 to $57 \mathrm{~mm}$ ) in females $(\mathrm{p}=0.00)$ (Table 2). There were no significant differences between measurements taken from each patient's right and left sides (Tables 3 and 4). There was no significant difference in the proportion of acetabular or femoral dysplasia between the sexes.

There was no significant intraobserver $(\mathrm{P}=0.72$, Wilcoxon rank test $)$ or interobserver error $(P=0.19$, Friedman test).

\section{Discussion}

This study has demonstrated significant differences in the femoral offset and acetabular version between males and females, with no significant differences between the other pelvic morphological parameters. Males had a greater femoral offset, and females had greater acetabular version. These results differ from the literature where females have been reported as having greater femoral neck anteversion and lower femoral neck-shaft angles [12-17]. This discrepancy may be the result of 
Table 1 Demonstrates no differences in femoral torsion or femoral neck angle between the sexes

\begin{tabular}{llllll}
\hline & Sex & N & Mean Rank & Sum of Ranks & Significance \\
\hline Femoral Torsion/deg & Male & 61 & 45.04 & 2522.00 & Z $=-0.865$ \\
& Female & 39 & 49.97 & 1849.00 & $\mathrm{p}=0.387$ \\
& Total & 100 & & & No significance \\
\hline Femoral Neck Angle/deg & Male & 61 & 137.43 & 2656.00 & Z $=-0.189$ \\
& Female & 39 & 136.35 & 1715.00 & $\mathrm{p}=0.850$ \\
& Total & 100 & & & No significance \\
\hline
\end{tabular}

Table 2 Demonstrates differences in the acetabular version and femoral offset between the sexes

\begin{tabular}{llllllll}
\hline & Sex & $\mathbf{N}$ & Mean & Std. Deviation & Std. Error Mean & Significance t-test and $\mathbf{p}$ & Significance \\
\hline Acetabular Version/deg & Male & 61 & 17.2 & 9.28 & 1.240 & $\mathrm{t}=2.320$ & $\mathbf{p}$ \\
& Female & 39 & 22.59 & 10.33 & 1.698 & $\mathbf{0 . 0 2 3}$ & $*$ \\
\hline Acetabular Inclination/deg & Male & 61 & 54.89 & 7.23 & 0.967 & $\mathrm{t}=-1.115$ & None \\
& Female & 39 & 56.65 & 7.73 & 1.270 & $\mathrm{p}=0.260$ & * \\
\hline Femoral Offset/mm & Male & 61 & 55.36 & 5.82 & 0.778 & $\mathbf{p}=\mathbf{0 . 0 0 0}$ & $* 000$ \\
& Female & 39 & 48.17 & 5.19 & 0.853 & & $*$ \\
\end{tabular}

* Females have greater acetabular version.

** Males have a greater femoral offset.

Table 3 Demonstrates no significant differences between measurements taken from each patient's right and left hips

\begin{tabular}{llllllll}
\hline & Paired Samples Statistics & Mean & N & Std. Deviation & Std. Error Mean & Significance & Significance \\
\hline Pair 1 & Acetabular Version/deg & 70.08 & 100 & 10.11 & 1.69 & 1.84 & $\mathrm{t}=1.546$ \\
& Acetabular Version/deg & 68.72 & 100 & 11.01 & $\mathrm{p}=0.131$ & No \\
Pair 2 & Acetabular Inclination/deg & 56.50 & 100 & 7.09 & 1.18 & $\mathrm{t}=0.199$ & No \\
& Acetabular Inclination/deg & 56.31 & 100 & 8.85 & 1.47 & $\mathrm{p}=0.844$ & No \\
Pair 3 & Femoral Offset/mm & 52.14 & 100 & 6.79 & 1.13 & $\mathrm{t}=0.799$ & $\mathrm{p}=0.430$ \\
& Femoral Offset/mm & 51.66 & 100 & 6.71 & 1.12 & & \\
\hline
\end{tabular}

Table 4 Demonstrates no significant differences between measurements taken from each patient's right and left hips

\begin{tabular}{lll}
\hline Test Statistics $^{c}$ & & \\
\hline & Femoral Torsion/deg - Femoral Torsion/deg & Femoral Neck Angle/deg - Femoral Neck Angle/deg \\
\hline$Z$ & $-1.40^{\mathrm{a}}$ & $-0.995^{\mathrm{b}}$ \\
Asymp. Sig. (2-tailed) & 0.161 & 0.320 \\
\hline
\end{tabular}

a. Based on negative ranks.

b. Based on positive ranks.

c. Wilcoxon Signed Ranks Test.

the racial uniformity seen in our patient group; certainly racial variations in hip morphology have been previously reported [20,21]. A study of 50 white women and 50 black women found that hip axis length and the neck width were significantly longer in the white women, while neck/shaft angles were not statistically different in the two groups [20].

This study also found no significant differences in morphology between patients' right and left hips, which is also contrary to findings from another study which concluded that side-specific prostheses should be manufactured [22].

While adjustments to anatomically restore the femoral offset and femoral version are possible using modular neck prostheses in total hip arthroplasty [12], we believe that attention should also be paid to the natural acetabular version. We emphasise the importance of pre-operative CT scanning in accurately determining these parameters, to allow for optimum component positioning, particular in the context of hip resurfacing arthroplasty. 


\section{Consent}

Written informed consent was obtained from all patients for their data inclusion in this and other research at our Institution. Copies of these consent forms are available for review by the Editor-in-Chief of this journal

\section{Abbreviations \\ CT: Computed Tomography}

\section{Acknowledgements}

The authors would like to thanks Belinda Grygorcewicz, St Andrews Hospital Radiology Department, 350 South Terrace, Adelaide SA 5000 for all her assistance in the data collection

\section{Author details}

'Department of Trauma and Orthopaedics and North London Sports Orthopaedics, North Middlesex University Hospital, Sterling Way, London N18 1QX, UK. ${ }^{2}$ Sportsmed SA, 32 Payneham Road, Stepney 5069, Adelaide, South Australia, Australia. ${ }^{3}$ St Andrews Hospital Radiology Department, 350 South Terrace, Adelaide SA 5000, Australia.

\section{Authors' contributions}

All the patients underwent arthroplasty surgery by RO. HA wrote the manuscript. HA, SZ and CWO defined and measured the radiological parameters. KJ assisted with the literature review and manuscript preparation. All authors have read and approved the final manuscript.

\section{Competing interests}

The authors declare that they have no competing interests.

Received: 14 May 2010 Accepted: 15 October 2010

Published: 15 October 2010

\section{References}

1. Treacy RBC, McBryde CW, Pynsent PB: Birmingham hip resurfacing arthroplasty. A minimum of five years follow up. J Bone Joint Surg $[\mathrm{Br}]$ 2005, 87(2):167-70

2. Wagner $\mathrm{H}$ : Surface replacement arthroplasty of the hip. Clin Orthop Relat Res 1978, 134: 102-30

3. Shimmin AJ, Back D: Femoral neck fractures following Birmingham hip resurfacing. J Bone Joint Surg [Br] 2005, 87-B:463-4.

4. Malviya A, Lingard EA, Malik A, Bowman R, Holland JP: Hip Flexion After Birmingham Hip Resurfacing: Role of Cup Anteversion, Anterior Femoral Head-Neck Offset, and Head-Neck Ratio. J Arthroplasty 2010, 25(3):387-91.

5. Hermann $\mathrm{KL}$, Egund $\mathrm{N}$ : Measuring anteversion in the femoral neck from routine radiographs. Acta Radiol 1998, 39(4):410-5.

6. Jamali AA, Mladenov K, Meyer DC, Martinez A, Beck M, Ganz R, Leunig M: Anteroposterior pelvic radiographs to assess acetabular retroversion: high validity of the "cross-over-sign". J Orthop Res 2007, 25(6):758-65.

7. Hermann $\mathrm{KL}$, Egund $\mathrm{N}$ : CT measurement of anteversion in the femoral neck. The influence of femur positioning. Acta Radiol 1997, 38(4 Pt 1):527-32.

8. Bailey C, Gul R, Falworth M, Zadow S, Oakeshott R: Component alignment in hip resurfacing using computer navigation. Clin Orthop Relat Res 2009, 467(4):917-22.

9. Torricelli P, Reggiani G, Martinelli C, Boriani S, Folchi Vici F: Value and limitations of computerized tomography in the study of benign tumors of the bone. Radiol Med 1987, 74(5):388-95.

10. Upadhyay SS, Burwell RG, Moulton A, Small PG, Wallace WA: Femoral anteversion in healthy children. Application of a new method using ultrasound. J Anat 1990, 169:49-61.

11. Nagar M, Bhardwaj R, Prakash R: Anteversion In Adult Indian Femora. Journal of the Anatomical Society of India 49(1), (2000-01 - 2000-06).

12. Traina F, De Clerico M, Biondi F, Pilla F, Tassinari E, Toni A: Sex differences in hip morphology: is stem modularity effective for total hip replacement? J Bone Joint Surg Am 2009, 91(Suppl 6):121-8.
13. Nieves JW, Formica C, Ruffing J, Zion M, Garrett P, Lindsay R, Cosman F: Males have larger skeletal size and bone mass than females, despite comparable body size. J Bone Miner Res 2005, 20:529-35.

14. Noble PC, Alexander JW, Lindahl L, Yew DT, Granberry WM, Tullos HS: The anatomic basis of femoral component design. Clin Orthop Relat Res 1988, 235:148-65.

15. Wang SC, Brede C, Lange D, Poster CS, Lange AW, Kohoyda-Inglis C, Sochor MR, Ipaktchi K, Rowe SA, Patel S, Garton HJ: Gender differences in hip anatomy:possible implications for injury tolerance in frontal collisions. Annu Proc Assoc Adv Automot Med 2004, 48:287-301.

16. Kaptoge S, Dalzell N, Loveridge N, Beck TJ, Khaw KT, Reeve J: Effects of gender, anthropometric variables, and aging on the evolution of hip strength in men and women aged over 65. Bone 2003, 32:561-70.

17. Sariali E, Mouttet A, Pasquier G, Durante E: Three-dimensional hip anatomy inosteoarthritis analysis of the femoral offset. J Arthroplasty 2009, 24:990-7.

18. Murray DW: The definition and measurement of acetabular orientation. J Bone Joint Surg Br 1993, 75(2):228-32.

19. Lecerf G, Fessy MH, Philippot R, Massin P, Giraud F, Flecher X, Girard J, Mertl P, Marchetti E, Stindel E: Femoral offset: Anatomical concept, definition, assessment, implications for preoperative templating and hip arthroplasty. Orthopaedics \& Traumatology: Surgery \& Research 2009, 95(3):210-219.

20. Lavy CB, Msamati BC, Igbigbi PS: Racial and gender variations in adult hip morphology. Int Orthop 2003, 27(6):331-3.

21. Mikhail MB, Vaswani AN, Aloia JF: Racial differences in femoral dimensions and their relation to hip fracture. Osteoporos Int 1996, 6(1):22-4.

22. Vandenbussche E, Saffarini M, Taillieu F, Mutschler C: The Asymmetric Profile of the Acetabulum. Clin Orthop Relat Res 2008, 466(2):417-423.

doi:10.1186/1749-799X-5-76

Cite this article as: Atkinson et al:: Differences in hip morphology between the sexes in patients undergoing hip resurfacing. Journal of Orthopaedic Surgery and Research 2010 5:76.

\section{Submit your next manuscript to BioMed Central and take full advantage of:}

- Convenient online submission

- Thorough peer review

- No space constraints or color figure charges

- Immediate publication on acceptance

- Inclusion in PubMed, CAS, Scopus and Google Scholar

- Research which is freely available for redistribution

Submit your manuscript at www.biomedcentral.com/submit
C Biomed Central 